OPEN ACCESS

Edited by:

Slavica Vuckovic

The University of

Queensland, Australia

Reviewed by:

Tuna Mutis,

Amsterdam University Medical

Center, Netherlands

Jakub Krejcik,

Odense University Hospital, Denmark

*Correspondence:

Criselle D'Souza

criselle.dsouza@petermac.org

Paul J. Neeson

paul.neeson@petermac.org

Specialty section:

This article was submitted to Cancer Immunity and Immunotherapy,

a section of the journal

Frontiers in Immunology

Received: 23 November 2020

Accepted: 15 February 2021

Published: 05 March 2021

Citation:

D'Souza C, Prince HM and Neeson PJ (2021) Understanding the Role of T-Cells in the Antimyeloma Effect of Immunomodulatory Drugs.

Front. Immunol. 12:632399. doi: 10.3389/fimmu.2021.632399

\section{Understanding the Role of T-Cells in the Antimyeloma Effect of Immunomodulatory Drugs}

\author{
Criselle D'Souza ${ }^{1,2 *}$, H. Miles Prince ${ }^{1,2,3}$ and Paul J. Neeson ${ }^{1,2 *}$ \\ ' Cancer Immunology Program, Peter MacCallum Cancer Centre, Melbourne, VIC, Australia, ${ }^{2}$ Sir Peter MacCallum \\ Department of Oncology, University of Melbourne, Melbourne, VIC, Australia, ${ }^{3}$ Clinical Hematology, Peter MacCallum Cancer \\ Centre and Royal Melbourne Hospital, Melbourne, VIC, Australia
}

Immunomodulatory drugs (IMiDs) are effective treatments for patients with multiple myeloma. IMiDs have pleotropic effects including targeting the myeloma cells directly, and improving the anti-myeloma immune response. In the absence of myeloma cells, lenalidomide and pomalidomide induce $\mathrm{CD}^{+}{ }^{+} \mathrm{T}$ cell secretion of IL-2 and indirect activation of Natural Killer (NK) cells. In the context of T cell receptor ligation, IMiDs enhance $\mathrm{T}$ cell proliferation, cytokine release and Th1 responses, both in vivo and in vitro. Furthermore, combination treatment of IMiDs and myeloma-targeting monoclonal antibodies eg. daratumumab (anti-CD38) and elotuzumab (anti-SLAMF7), checkpoint inhibitors, or bispecific T cell engagers showed synergistic effects, mainly via enhanced $\mathrm{T}$ and NK cell dependent cellular toxicity and $\mathrm{T}$ cell proliferation. Conversely, the corticosteroid dexamethasone can impair the immune modulatory effects of IMiDs, indicating that careful choice of myeloma drugs in combination with IMiDs is key for the best anti-myeloma therapeutic efficacy. This review presents an overview of the role for $T$ cells in the overall anti-myeloma effects of immunomodulatory drugs.

Keywords: immunomodulatory drugs, myeloma, T cells, NK cells, immunotherapy

\section{INTRODUCTION}

Multiple myeloma (MM) is a plasma B cell malignancy primarily localized to the bone marrow and characterized by immune dysfunction due to the complex interplay between the malignant plasma cells (PC) and immune cells in the tumor microenvironment (1). New therapeutic approaches in the last two decades have dramatically improved patient outcomes. These include the incorporation of immunomodulatory drugs (IMiDs) that exert pleiotropic effects including directly acting on the malignant cells and enhancing $\mathrm{T}$ and NK cell anti-myeloma properties (2).

\section{IMMUNOMODULATORY DRUGS}

IMiDs, namely lenalidomide and pomalidomide are a group of drugs that are derivatives from thalidomide, a glutamic acid derivative (2). Thalidomide use in clinical trials of advanced MM was first published in 1999 and soon it was utilized, alone and in combination, across all phases of myeloma therapy (3). Due to its problematic side effects and improved efficacy of the subsequent IMiDs, thalidomide has progressively been replaced by lenalidomide and pomalidomide in the myeloma treatment paradigm; currently IMiDs are used in newly diagnosed MM (NDMM) patients, in maintenance therapy post autologous stem cell transplantation and in patients with relapsed refractory multiple myeloma (RRMM) (4). 
IMiDs were first shown to have anti-angiogenic activities and anti-inflammatory anti-tumor necrosis factor (TNF)- $\alpha$ activity in monocytes (5). Although, IMiDs suppress TNF $\alpha$ production by monocytes (5), they have an opposite effect on T cells, where they increase TNF $\alpha$ production (6). IMiDs also directly act on myeloma cells, affecting their proliferative capacity (7).

\section{MECHANISM OF ACTION}

IMiDs bind to Cereblon (CRBN), DDB1, CUL4 and ROC1 and together form an E3 ubiquitin ligase, which modify multiple proteins causing ubiquitination and proteasome degradation of these target proteins (8). IMiDs cause selective degradation and downregulation of two CRBN-binding lymphocyte transcription factors IKZF1 (Ikaros) and IKZF3 (Aiolos), which leads to an increase in interleukin (IL)-2 production in T cells (8) and mechanism reviewed in detail in (9). In addition, IMiDs can also cause immune activation by stimulating NK cells, and inhibiting IL-6 production from monocytes and macrophages $(10,11)$.

CRBN-binding protein Casein kinase 1 alpha (CK1a) is degraded upon IMiD treatment. CK1a is known to facilitate MM pathogenesis as it sustains activation of oncogenic cascades through p53 activation, phosphoinositide-3-kinase (PI3K) / protein kinase $\mathrm{B}(\mathrm{AKT})$ and nuclear factor kappa B (NF-кB) activation and modulation of interferon (IFN) pathway $(12,13)$.

\section{MULTIPLE MYELOMA DEVELOPMENT LEADS TO IMMUNE DYSFUNCTION}

Several studies have shown that myeloma cell survival and immune escape is facilitated by impaired endogenous signaling in immune cells $(2,14)$. These include defects in T cell distribution and function, a reduction of peripheral blood $\mathrm{CD} 4^{+}$and $\mathrm{CD} 8^{+}$ $\mathrm{T}$ cells, abnormal Th1/Th2 ratio, decrease in the CD4/CD8 T cell ratio with reduced or aberrant $\mathrm{T}$ cell function, and reduction in NKT cells (14). Myeloma cells are known to secrete transforming growth factor (TGF)- $\beta$, a highly immunosuppressive cytokine that inhibits $\mathrm{T}$ and $\mathrm{NK}$ cell function and cytotoxicity. The compartment in which these cells are residing/trafficking may be relevant. Indeed, a recent study demonstrated that at the tumor site within the bone marrow, $\mathrm{T}$ cells are immune-suppressed, largely exhausted and senescent (15).

MM production of TGF- $\beta$, IL-10, IL-6, and VEGF also leads to impaired DC antigen presentation to $\mathrm{T}$ cells, affecting $\mathrm{T}$ cell priming $(16,17)$. Myeloid and plasmacytoid dendritic cells (DCs) from MM patients have lower expression of human leucocyte antigen (HLA) molecules, C-C chemokine receptor (CCR)-5, CCR7, and DEC205 (18). This further leads to a suboptimal immune response toward tumor cells. Some reports suggest regulatory T cells (Tregs), a subset of immune-suppressive CD $4^{+}$ $\mathrm{T}$ cells, to be increased in MM patients $(19,20)$. However, this is controversial as there are also conflicting reports with lower numbers of Tregs in patients than healthy controls (21). These discrepancies could be due to technical issues with absolute counts and percentages of cells, if particular subsets of $\mathrm{CD} 4^{+} \mathrm{T}$ cells are reduced. This could also be related to dexamethasone treatment. There is also a skewing of Treg/Th17 balance in $\mathrm{MM}$ and this further increases immune suppression leading to poor prognosis in patients $(22,23)$. Overall, immune evasion of tumor cells is associated with myeloma cell proliferation and leads to MM pathogenesis. Treatments that can reverse these defects in combination with other treatments such as monoclonal antibodies have shown the most promise in treating MM in currently approved therapies.

\section{IMMUNE MODULATION BY IMIDS}

In vitro studies have shown that treatment with IMiDs enhanced T cell proliferation, IL- 2 and IFN- $\gamma$ secretion and NK and NKT cell activation $(24,25)$. IMiDs such as thalidomide downregulated IL-6 from peripheral blood mononuclear cells (PBMC) and IL10 production from $\mathrm{T}$ cells and induced co-stimulation of $\mathrm{CD} 4^{+}$ and $\mathrm{CD}^{+} \mathrm{T}$ cells in in-vitro assays (10). Pomalidomide and lenalidomide are 300-1,200 times more potent than thalidomide at inducing $\mathrm{T}$ cell proliferation, IL- 2 and IFN- $\gamma$ production $(10,24)$. IMiDs enhanced DC-antigen presentation leading to activation of $\mathrm{CD}^{+}$and $\mathrm{CD} 4^{+} \mathrm{T}$ cells and production of IFN$\gamma(26,27)$. IMiDs also stimulated CD28 downstream signaling by binding to $\mathrm{B} 7$ co-stimulatory molecule, reducing myeloma immune tolerance (28). IMiDs enhanced expression of DNAbinding protein AP-1, which in turn causes CD28 signaling and stimulation of nuclear factor of activated T-cells (NFAT) $(2,28$, 29). This leads to production of IL-2 inducing $T$ cell proliferation and activation and also NK cell activation (29).

In vivo, IMiDs were shown to increase endogenous tumor-specific $\mathrm{T}$ cell and $\mathrm{NK}$ cell immunity as well as in vaccine responses (30).

\section{CYTOTOXIC CD8+ ${ }^{+}$CELLS}

Studies have shown that central and effector memory $\mathrm{CD} 8^{+}$ $\mathrm{T}$ cells, Tregs and myeloid derived suppressor cells (MDSC) increased after lenalidomide treatment (31). Thus, indicating that lenalidomide treatment can induce both activating and inhibitory immune responses. However, the inhibitory effects observed could be due to dexamethasone (an immunosuppressant) combination treatment that was used for some patients in this study. Indeed, we have previously showed that high dose dexamethasone abrogates immune activating effects of lenalidomide (32).

Myeloma patients that received bortezomib treatment followed by lenalidomide maintenance treatment post autologous stem cell transplant (ASCT) showed increase in naïve and memory $\mathrm{CD}^{+} \mathrm{T}$ cells, higher expression of costimulatory molecules and reduction in inhibitory checkpoint molecules (33). However, an increase in Treg cells was also observed in this study. Anti-myeloma specific T cell responses with increased secretion of IFN- $\gamma$, perforin and granzyme B were observed in a clinical trial of myeloma patients that received lenalidomide as consolidation therapy after ASCT (34).

In newly diagnosed patients, lenalidomide treatment after ASCT impaired long-term thymic $\mathrm{T}$ cell reconstitution, with 
a decrease in $\mathrm{CD}^{+}$and $\mathrm{CD}^{+}$effector $\mathrm{T}$ cell counts (618 months post graft) and increase in Tregs (9-18 months post graft) $(33,35)$. Lenalidomide maintenance treatment also reduced programmed cell death protein 1 (PD-1) expression on $\mathrm{CD}^{+} \mathrm{T}$ cells, suggesting that it has the potential to counter-act the myeloma induced exhaustion or senescence on $\mathrm{T}$ cells (36). However, an alternate explanation is that lenalidomide maintenance treatment maintains low minimal residual disease, leading to lower antigen stimulation and reduced $\mathrm{T}$ cell exhaustion.

\section{$\mathrm{CD}^{+}{ }^{+} \mathrm{T}$ HELPER CELLS AND TREG CELLS}

In the context of ASCT, IMiDs (with dexamethasone and bortezimib) treatment during induction chemotherapy has been shown to play a role in reducing the pro-tumor Th17-Th1 and Th22 cells in the bone marrow, concurrently with reduction in cytokine levels of IL-17, IL-22, and IL-6, TNF- $\alpha$, IL-1 $\beta$, and IL23 (37). This correlated with a favorable clinical outcome (37). There was no difference in the number of Tregs between treated and untreated or between diagnosis and transplantation in this study (37). However, previous studies showed an increase or decrease in Treg numbers in patients treated with lenalidomide and dexamethasone (38-40). In in-vitro assays, lenalidomide and pomalidomide inhibited IL-2 mediated generation of Tregs from PBMCs with marked reduction in suppressor function (41). In a post-transplant setting, peripheral blood Tregs declined in patients treated with IMiDs during induction therapy pre-ASCT as CD8 T cells expanded (38). In contrast, another study showed that Treg numbers increased in relapsed patients when treated with lenalidomide post allogeneic stem cell transplant (allo-SCT) and with $46 \%$ of the patients responding to the therapy (39). Thus, further highlighting the discrepancies observed in different studies on the role of IMiDs on Tregs.

\section{EFFECT OF IMIDS ON NK AND INVARIANT NATURAL KILLER T CELLS}

NK cells play an important role in tumor immunity. However, they are dysfunctional in myeloma (1). The immune suppressive myeloma microenvironment has elevated IL-10 and TGFbeta, and was associated with decreased expression of $\mathrm{NK}$ activating receptors, TNF and IFN- $\gamma$ secretion, and impaired NK cytotoxicity toward myeloma $(1,42,43)$.

Multiple studies demonstrated IMiDs enhanced the activity and function of NK and invariant NKT cells in multiple myeloma $(24,29,44,45)$. Lenalidomide enhanced direct NK cell cytotoxicity and NK-dependent antibody dependent cellular cytotoxicity (ADCC) (24). However, our study showed that combination treatment with high dose dexamethasone abrogates this lenalidomide induced NK cell function (32). Lenalidomide enhances NK cell cytotoxicity by $\mathrm{CD} 4^{+} \mathrm{T}$ cell production of IL-2 and dexamethasone suppresses this IL-2 production (32).

Combination treatment of IMiDs and monoclonal antibodies elotuzumab (anti-SLAMF7) or daratumumab (anti-CD38) and isatuximab (anti-CD38) showed synergistic effects in enhancing
NK cell activity and efficacy in clinical trials (46-50). This is through enhancing NK ADCC, monocyte/macrophage mediated antibody dependent cellular phagocytocis (ADCP) and apoptosis (1). In phase $1 / 2$ study of combination therapy of daratumumab, lenalidomide and dexamethasone in refractory relapsed MM patients, an overall response rate of $81 \%$ was achieved (51). In a phase 3 trial, patients that received the daratumumab, lenalidomide and dexamethasone, a higher overall response and progression free survival rate as compared to the lenalidomide and dexamethasone group (49). In phase 1 and phase II studies, patients with RRMM that received combination of elotuzumab, lenalidomide and dexamethasone had a $30 \%$ reduction in disease progression or death without significant toxicity $(52,53)$. These treatment strategies demonstrate that combining IMiDs with monoclonal antibodies are effective for RRMM.

Invariant NKT cells are CD1d restricted $\mathrm{T}$ cells that recognize glycolipid antigens. Invariant NKT cells respond to $\alpha$ galactosylceramide (NKT cell antigen) pulsed primary myeloma cells, with release of cytokines and tumor cell lysis (54). MM patients treated with lenalidomide showed increased invariant NKT cell frequency with cytokine responses. Patients with refractory disease have a marked decrease in invariant NKT cell frequency (45). However, no difference in invariant NKT cell numbers were observed in newly diagnosed MM patients (45). Lenalidomide induction or maintenance therapy did not seem to have any effect on invariant NKT cell frequency and numbers (45). Thus, suggesting that lenalidomide benefits are not dependent on invariant NKT cells.

\section{IMPACT OF COMBINATION TREATMENT WITH IMIDS ON T CELLS}

Immune checkpoint molecules such as cytotoxic T-lymphocyteassociated protein 4 (CTLA-4), PD-1 and lymphocyte activation gene 3 (LAG-3) diminish $\mathrm{T}$ cell responses and play a major role in peripheral tolerance to antigens and preventing autoimmune disease. In myeloma, PD-1 is expressed on bone marrow and peripheral blood $\mathrm{CD}^{+} \mathrm{T}$ cells and NK cells $(55,56)$. The PD-1 ligand (PD-L1) is expressed on malignant myeloma cells, bone marrow MDSC and PD-L1 is upregulated on interaction with bone marrow stromal cells (BMSC) $(57,58)$. Thus, indicating that the PD1-PDL1 axis can be targeted as a treatment strategy.

In in-vitro studies, single blockade using an antibody against PD-1 or dual blockade using antibodies against PD1 and PD-L1 with lenalidomide induced anti-myeloma immune response by blocking the cross-talk between BMSC and myeloma cells, thus reducing myeloma growth (55). A phase 1 trial of pembrolizumab (anti-PD-1 antibody) in combination with lenalidomide and dexamethasone showed a $50 \%$ overall response rate (59). A phase 2 trial with the same combination showed an overall response rate of $60 \%$ in refractory relapsed patients (60). However, a phase 3 trial (KEYNOTE-183 and KEYNOTE-185) evaluating pembrolizmab with lenalidomide and dexamethasone in newly diagnosed patients was discontinued due to unexpected higher risk of death (61). Other ongoing trials involving immune checkpoint 


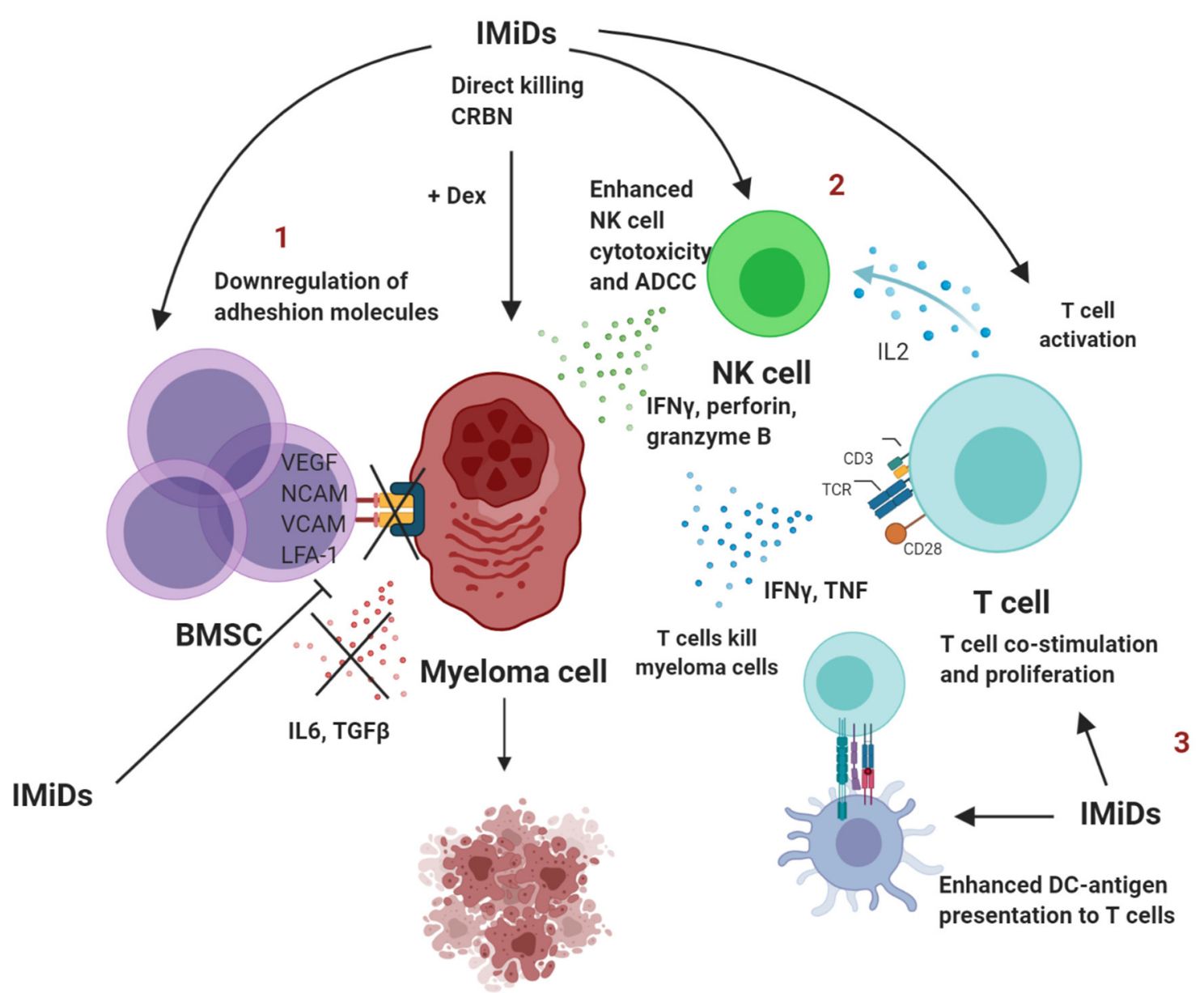

Myeloma cell death

FIGURE 1 | Summary of immunomodulatory effects of IMiDs in multiple myeloma. 1. IMiDs directly act by downregulating adhesion molecules that disrupt the BMSC-myeloma interaction, which further leads to reduced production of IL-6 and TGF $\beta$ and conversion to a less immune-suppressed TME. 2. IMiDs enhance IL-2 production by $\mathrm{CD}^{+}{ }^{+} \mathrm{T}$ cells that in turn lead to NK cell activation and proliferation. IMiDs also enhance direct cellular cytotoxicity and ADCC. 3. IMiDs enhance DC-T cell antigen presentation and co-stimulation through the CD28 pathway. T cells secrete higher amounts of IL-2, IFN $\gamma$ and TNF. BMSC, bone marrow stromal cells; DC, dendritic cells; NK, Natural killer; IL, interleukin; TGF, transforming growth factor; ADCC, antibody-dependent cellular toxicity; dex, dexamethasone; IFN, Interferon; TNF, tumor necrosis factor. Created with BioRender.com.

inhibitors in NDMM patients were stopped based on this warning (62). Therefore, despite some trials showing a safe response, in light of the phase 3 trials described above, the safety concerns of the PD1/PDL1 inhibitors in combination with IMiDs led the FDA to terminate all trials using these combinations [reviewed in detail (62)].

A vaccine approach that used DCs fused with tumor cells demonstrated an increase in myeloma specific $\mathrm{T}$ cells, in a phase II study in the post ASCT setting (63). Combining IMiDs with this vaccine may further enhance the response to the DC fusion vaccine therapy. Indeed, combination treatment of a vaccine targeting the EGFR pathway substrate (Eps8) antigen on myeloma cells with lenalidomide enhanced the tumor-specific cytotoxic $\mathrm{T}$ cell response and increased survival in patients (64).

\section{IMIDS EFFECTS ON THE TUMOR MICROENVIRONMENT AND MYELOMA CELLS}

The BMSC and the extracellular matrix (ECM) proteins such as CD44, VLA-4, LFA-1, VCAM, NCAM, and ICAM-1 are critical for the malignant PC survival (65). The interaction between the BMSC and PC is via cell-cell contact and production of cytokines such as IL-6, which promote PC survival. Adhesion of MM cells to BMSC enhances expression of IL-6 and VEGF (66). IMiDs inhibit production of $\mathrm{TNF} \alpha$, which in turn reduces the production of IL-6 (67). IMiDs downregulate surface adhesion molecules, which inhibit the MM-BMSC interaction and reduce the pro-survival cytokine production (67). IMiDs also exert direct 
effects on PC proliferation via inhibition of the cyclin-dependent kinase pathway and activation of Fas-mediated cell death (2).

The inhibition of PC survival by IMiDs restores immune homeostasis and thus reduces the presence of senescent or exhausted $\mathrm{T}$ cells in the bone marrow. A summary of the immunomodulatory effects of IMiDs are outlined in Figure 1.

\section{RESISTANCE TO IMIDS}

Treatment with IMiDs has improved survival of MM patients and is now a standard of care treatment (68). However, a subset of patients relapse and are refractory to IMiDs over time (69). One of the mechanisms that has been identified is through the CRBN pathway, which is a known primary target of IMiDs mediated degradation and ubiquitination as explained earlier (70). High expression of CRBN has been associated with improved clinical response in IMiD treated patients $(70,71)$. Patients with lenalidomide resistance express lower levels of CRBN than lenalidomide sensitive patients $(70,71)$.

A recent study has reported that RUNX transcription factor proteins, RUNX1 and RUNX3 interact with the transcription factor proteins, IKZF1 and IKZF3 (substrates for CRBN binding), which protects them from CRBN-dependent degradation that is induced by IMiDs (72). Other signaling pathways have been identified for IMiD resistance in myeloma cells. These include the Wnt/B-catenin (73), MEK/ERK (74), or STAT3 pathways (75). Overall, all the pathways identified for resistance to IMiDs are in myeloma cells. This may in turn affect the micro-environment leading to immune dysregulation. However, further studies are required to demonstrate whether IMiD resistance in myeloma cells, affects their capacity to inhibit $\mathrm{T}$ and $\mathrm{NK}$ cell function.

\section{OVERCOMING RESISTANCE TO IMIDS}

New IMiDs known as CELMoDs (CRBN modulating agents) have been recently developed; these drugs have a more specific activity than IMiDs and are engineered to target specific proteins for rapid and efficient degradation (76). These CELMoDs can be used in patients that are refractory to previous lines of treatment that include lenalidomide and pomalidomide (76). These new CELMoDs include avodomide (CC-122) and iberdomide (CC220) $(77,78)$. Avadomide has shown acceptable safety and pharmacokinetics in myeloma patients (78). Iberdomide is an E3 ligase cereblon modulator that mediates anti-proliferative and immunostimulatory activity in lenalidomide and pomalidomide resistant cell lines (79). Combination of iberdomide with daratumumab showed superior cytotoxicity against myeloma cell lines than either drug alone (79). In early results of an ongoing phase 1/2 clinical trial (NCT02773030), iberdomide plus dexamethasone showed favorable efficacy and safety in pre-treated RRMM patients who failed previous treatments, including pomalidomide, lenalidomide, and daratumumab (77). In other arms of the trial, iberdomide plus daratumumab plus dexamethasone (IberDd) and iberdomide plus bortezimib plus dexamethasone (IberVd), showed favorable tolerability with an overall response rate of $35 \%$ across both groups (80). These results demonstrate that triplet combination therapy may have clinical benefits in heavily pre-treated refractory patients. Further phase 3 trials are needed to evaluate these triplet combinations.

Other strategies have been tested to overcome IMiD resistance in in-vitro assays against myeloma cell lines resistant to IMiDs. These include STAT-3 inhibitor (PB-1-102) and MEK1/2 inhibitor, demonstrating the importance of these pathways in resistance to IMiDs (75). As RUNX proteins protect IKZF1 and IKZF3 from degradation, inhibition of RUNX resulted in sensitization of myeloma cell lines and primary tumors resistant to lenalidomide (72). Epigenetic modulators such as 5-Azacytidine (DNA methyltransferase inhibitor) and EZH2 inhibitor re-sensitized IMiD-resistant myeloma cells through extensive epigenetic reprogramming and independent of CRBN (81). However, the exact mechanism is still unknown.

\section{CONCLUSION}

Treatment with IMiDs, especially in combination with other therapeutic drugs has dramatically improved the outcomes of patients with MM, both for newly diagnosed and refractory relapsed patients. IMiDs exert their action through multiple pathways. Immune modulation by enhancing the function of immune cells such as $\mathrm{T}$ and $\mathrm{NK}$ cells are a major pathway of their mode of action.

Newer therapies such as bispecific antibodies and chimeric antigen receptor (CAR)-T cell therapies are currently in clinical trials and are showing promising results in treating myeloma [reviewed in $(82,83)]$. Both of these approaches target specific antigens on myeloma cells and work through CD3 stimulation (bispecific antibodies) or CAR on $\mathrm{T}$ cells, but independent of their $\mathrm{T}$ cell receptor $(82,83)$. Both of these therapies use $\mathrm{T}$ cells from myeloma patients, which are senescent or enriched in Tregs (as discussed in previous sections). IMiDs can reverse some of these defects in the $\mathrm{T}$ cells and restore immune homeostasis. Therefore, future therapeutic approaches could involve combining IMiDs with CAR-T cell based approaches and bispecific engagers, reducing chances of relapse. Overall, combination approaches will avoid drug resistance that has been observed with single agents.

\section{AUTHOR CONTRIBUTIONS}

CD'S, HP, and PN co-wrote and edited the manuscript. All authors contributed to the article and approved the submitted version.

\section{FUNDING}

This work was supported by funding from NHMRC program grant number 11132373. 


\section{REFERENCES}

1. Pittari G, Vago L, Festuccia M, Bonini C, Mudawi D, Giaccone L, et al. Restoring natural killer cell immunity against multiple myeloma in the era of new drugs. Front Immunol. (2017) 8:1444. doi: 10.3389/fimmu.2017.01444

2. Quach H, Ritchie D, Stewart AK, Neeson P, Harrison S, Smyth MJ, et al. Mechanism of action of immunomodulatory drugs (IMiDS) in multiple myeloma. Leukemia. (2010) 24:22-32. doi: 10.1038/leu.2009.236

3. Singhal S, Mehta J, Desikan R, Ayers D, Roberson P, Eddlemon P, et al. Antitumor activity of thalidomide in refractory multiple myeloma. $N$ Engl J Med. (1999) 341:1565-71. doi: 10.1056/NEJM199911183412102

4. Abe Y, Ishida T. Immunomodulatory drugs in the treatment of multiple myeloma. Jpn J Clin Oncol. (2019) 49:695-702. doi: 10.1093/jjco/hyz083

5. Sampaio EP, Sarno EN, Galilly R, Cohn ZA, Kaplan G. Thalidomide selectively inhibits tumor necrosis factor alpha production by stimulated human monocytes. J Exp Med. (1991) 173:699-703. doi: 10.1084/jem.173.3.699

6. Haslett PA, Corral LG, Albert M, Kaplan G. Thalidomide costimulates primary human T lymphocytes, preferentially inducing proliferation, cytokine production, and cytotoxic responses in the CD8+ subset. J Exp Med. (1998) 187:1885-92. doi: 10.1084/jem.187.11.1885

7. Hideshima T, Chauhan D, Shima Y, Raje N, Davies FE, Tai YT, et al. Thalidomide and its analogs overcome drug resistance of human multiple myeloma cells to conventional therapy. Blood. (2000) 96:294350 doi: 10.1182/blood.V96.9.2943

8. Kronke J, Udeshi ND, Narla A, Grauman P, Hurst SN, McConkey M, et al. Lenalidomide causes selective degradation of IKZF1 and IKZF3 in multiple myeloma cells. Science. (2014) 343:301-5. doi: 10.1126/science.1244851

9. Kortum KM, Zhu YX, Shi CX, Jedlowski P, Stewart AK. Cereblon binding molecules in multiple myeloma. Blood Rev. (2015) 29:32934. doi: 10.1016/j.blre.2015.03.003

10. Corral LG, Haslett PA, Muller GW, Chen R, Wong LM, Ocampo CJ, et al. Differential cytokine modulation and $\mathrm{T}$ cell activation by two distinct classes of thalidomide analogues that are potent inhibitors of TNF-alpha. J Immunol. (1999) 163:380-6.

11. Zhu D, Corral LG, Fleming YW, Stein B. Immunomodulatory drugs Revlimid (lenalidomide) and CC-4047 induce apoptosis of both hematological and solid tumor cells through NK cell activation. Cancer Immunol Immunother. (2008) 57:1849-59. doi: 10.1007/s00262-008-0512-7

12. Manni S, Carrino M, Manzoni M, Gianesin K, Nunes SC, Costacurta M, et al. Inactivation of CK1alpha in multiple myeloma empowers drug cytotoxicity by affecting AKT and beta-catenin survival signaling pathways. Oncotarget. (2017) 8:14604-19. doi: 10.18632/oncotarget.14654

13. Manni S, Carrino M, Piazza F. Role of protein kinases CK1alpha and CK2 in multiple myeloma: regulation of pivotal survival and stress-managing pathways. J Hematol Oncol. (2017) 10:157. doi: 10.1186/s13045-017-0529-5

14. Joshua D, Suen H, Brown R, Bryant C, Ho PJ, Hart D, et al. The $\mathrm{T}$ cell in myeloma. Clin Lymphoma Myeloma Leuk. (2016) 16:53742. doi: 10.1016/j.clml.2016.08.003

15. Zelle-Rieser C, Thangavadivel S, Biedermann R, Brunner A, Stoitzner P, Willenbacher E, et al. $\mathrm{T}$ cells in multiple myeloma display features of exhaustion and senescence at the tumor site. J Hematol Oncol. (2016) 9:116. doi: 10.1186/s13045-016-0345-3

16. Turtle CJ, Brown RD, Joshua DE, Hart DN. DC in multiple myeloma immunotherapy. Cytotherapy. (2004) 6:12837. doi: 10.1080/14653240410005357

17. Brown RD, Pope B, Murray A, Esdale W, Sze DM, Gibson J, et al. Dendritic cells from patients with myeloma are numerically normal but functionally defective as they fail to up-regulate CD80 (B7-1) expression after huCD40LT stimulation because of inhibition by transforming growth factorbetal and interleukin-10. Blood. (2001) 98:2992-8. doi: 10.1182/blood.V98. 10.2992

18. Brimnes MK, Svane IM, Johnsen HE. Impaired functionality and phenotypic profile of dendritic cells from patients with multiple myeloma. Clin Exp Immunol. (2006) 144:76-84. doi: 10.1111/j.1365-2249.2006.03037.x

19. Beyer M, Kochanek M, Giese T, Endl E, Weihrauch MR, Knolle PA, et al. In vivo peripheral expansion of naive CD4+CD25high FoxP3+ regulatory T cells in patients with multiple myeloma. Blood. (2006) 107:39409. doi: 10.1182/blood-2005-09-3671
20. Feyler S, von Lilienfeld-Toal M, Jarmin S, Marles L, Rawstron A, Ashcroft $\mathrm{AJ}$, et al. $\mathrm{CD} 4(+) \mathrm{CD} 25(+) \mathrm{FoxP} 3(+)$ regulatory $\mathrm{T}$ cells are increased whilst CD3(+)CD4(-)CD8(-)alphabetaTCR $(+)$ double negative $\mathrm{T}$ cells are decreased in the peripheral blood of patients with multiple myeloma which correlates with disease burden. Br J Haematol. (2009) 144:68695. doi: 10.1111/j.1365-2141.2008.07530.x

21. Prabhala RH, Neri P, Bae JE, Tassone P, Shammas MA, Allam CK, et al. Dysfunctional T regulatory cells in multiple myeloma. Blood. (2006) 107:3014. doi: 10.1182/blood-2005-08-3101

22. Favaloro J, Brown R, Aklilu E, Yang S, Suen H, Hart D, et al. Myeloma skews regulatory $\mathrm{T}$ and pro-inflammatory $\mathrm{T}$ helper 17 cell balance in favor of a suppressive state. Leuk Lymphoma. (2014) 55:10908. doi: 10.3109/10428194.2013.825905

23. Bryant C, Suen H, Brown R, Yang S, Favaloro J, Aklilu E, et al. Long-term survival in multiple myeloma is associated with a distinct immunological profile, which includes proliferative cytotoxic T-cell clones and a favourable Treg/Th17 balance. Blood Cancer J. (2013) 3:e148. doi: 10.1038/bcj.2013.34

24. Davies FE, Raje N, Hideshima T, Lentzsch S, Young G, Tai YT, et al. Thalidomide and immunomodulatory derivatives augment natural killer cell cytotoxicity in multiple myeloma. Blood. (2001) 98:2106. doi: 10.1182/blood.V98.1.210

25. Luptakova K, Rosenblatt J, Glotzbecker B, Mills H, Stroopinsky D, Kufe T, et al. Lenalidomide enhances anti-myeloma cellular immunity. Cancer Immunol Immunother. (2013) 62:39-49. doi: 10.1007/s00262-012-1308-3

26. Castelli R, Cassin R, Cannavo A, Cugno M. Immunomodulatory drugs: new options for the treatment of myelodysplastic syndromes. Clin Lymphoma Myeloma Leuk. (2013) 13:1-7. doi: 10.1016/j.clml.2012.09.016

27. Henry JY, Labarthe MC, Meyer B, Dasgupta P, Dalgleish AG, Galustian C. Enhanced cross-priming of naive CD8+ T cells by dendritic cells treated by the $\operatorname{IMiDs}(\mathrm{R})$ immunomodulatory compounds lenalidomide and pomalidomide. Immunology. (2013) 139:377-85. doi: 10.1111/imm.12087

28. LeBlanc R, Hideshima T, Catley LP, Shringarpure R, Burger R, Mitsiades N, et al. Immunomodulatory drug costimulates $\mathrm{T}$ cells via the B7-CD28 pathway. Blood. (2004) 103:1787-90. doi: 10.1182/blood-2003-02-0361

29. Hayashi T, Hideshima T, Akiyama M, Podar K, Yasui $H$, Raje N, et al. Molecular mechanisms whereby immunomodulatory drugs activate natural killer cells: clinical application. Br J Haematol. (2005) 128:192203. doi: 10.1111/j.1365-2141.2004.05286.x

30. Noonan K, Rudraraju L, Ferguson A, Emerling A, Pasetti MF, Huff CA, et al. Lenalidomide-induced immunomodulation in multiple myeloma: impact on vaccines and antitumor responses. Clin Cancer Res. (2012) 18:142634. doi: 10.1158/1078-0432.CCR-11-1221

31. Busch A, Zeh D, Janzen V, Mugge LO, Wolf D, Fingerhut L, et al. Treatment with lenalidomide induces immunoactivating and counterregulatory immunosuppressive changes in myeloma patients. Clin Exp Immunol. (2014) 177:439-53. doi: 10.1111/cei.12343

32. Hsu AK, Quach H, Tai T, Prince HM, Harrison SJ, Trapani JA, et al. The immunostimulatory effect of lenalidomide on NK-cell function is profoundly inhibited by concurrent dexamethasone therapy. Blood. (2011) 117:160513. doi: 10.1182/blood-2010-04-278432

33. Fostier K, Caers J, Meuleman N, Broos K, Corthals J, Thielemans $\mathrm{K}$, et al. Impact of lenalidomide maintenance on the immune environment of multiple myeloma patients with low tumor burden after autologous stem cell transplantation. Oncotarget. (2018) 9:20476-89. doi: 10.18632/oncotarget.24944

34. Kramer I, Engelhardt M, Fichtner S, Neuber B, Medenhoff S, Bertsch $U$, et al. Lenalidomide enhances myeloma-specific Tcell responses in vivo and in vitro. Oncoimmunology. (2016) 5:e1139662. doi: 10.1080/2162402X.2016.1139662

35. Clave E, Douay C, Coman T, Busson M, Bompoint C, Moins-Teisserenc $\mathrm{H}$, et al. Lenalidomide consolidation and maintenance therapy after autologous stem cell transplant for multiple myeloma induces persistent changes in T-cell homeostasis. Leuk Lymphoma. (2014) 55:1788-95. doi: 10.3109/10428194.2013.865182

36. Danhof S, Schreder M, Knop S, Rasche L, Strifler S, Loffler C, et al. Expression of programmed death-1 on lymphocytes in myeloma patients is lowered during lenalidomide maintenance. Haematologica. (2018) 103:e126e9. doi: 10.3324/haematol.2017.178947 
37. Di Lullo G, Marcatti M, Heltai S, Tresoldi C, Paganoni AM, Bordignon $\mathrm{C}$, et al. Immunomodulatory drugs in the context of autologous hematopoietic stem cell transplantation associate with reduced protumor $\mathrm{T}$ cell subsets in multiple myeloma. Front Immunol. (2018) 9:3171. doi: 10.3389/fimmu.2018.03171

38. Chung DJ, Pronschinske KB, Shyer JA, Sharma S, Leung S, Curran SA, et al. T-cell exhaustion in multiple myeloma relapse after autotransplant: optimal timing of immunotherapy. Cancer Immunol Res. (2016) 4:6171. doi: 10.1158/2326-6066.CIR-15-0055

39. Minnema MC, van der Veer MS, Aarts T, Emmelot M, Mutis T, Lokhorst HM. Lenalidomide alone or in combination with dexamethasone is highly effective in patients with relapsed multiple myeloma following allogeneic stem cell transplantation and increases the frequency of CD4+Foxp3 $+\mathrm{T}$ cells. Leukemia. (2009) 23:605-7. doi: 10.1038/leu.2008.247

40. Scott GB, Carter C, Parrish C, Wood PM, Cook G. Downregulation of myeloma-induced ICOS-L and regulatory $\mathrm{T}$ cell generation by lenalidomide and dexamethasone therapy. Cell Immunol. (2015) 297:1-9. doi: 10.1016/j.cellimm.2015.05.002

41. Galustian C, Meyer B, Labarthe MC, Dredge K, Klaschka D, Henry J, et al. The anti-cancer agents lenalidomide and pomalidomide inhibit the proliferation and function of $\mathrm{T}$ regulatory cells. Cancer Immunol Immunother. (2009) 58:1033-45. doi: 10.1007/s00262-008-0620-4

42. Castriconi R, Cantoni C, Della Chiesa M, Vitale M, Marcenaro E, Conte $\mathrm{R}$, et al. Transforming growth factor beta 1 inhibits expression of NKp30 and NKG2D receptors: consequences for the NK-mediated killing of dendritic cells. Proc Natl Acad Sci USA. (2003) 100:41205. doi: 10.1073/pnas.0730640100

43. Lee JC, Lee KM, Kim DW, Heo DS. Elevated TGF-betal secretion and downmodulation of NKG2D underlies impaired NK cytotoxicity in cancer patients. J Immunol. (2004) 172:7335-40. doi: 10.4049/jimmunol.172.12.7335

44. Tai YT, Li XF, Catley L, Coffey R, Breitkreutz I, Bae J, et al. Immunomodulatory drug lenalidomide (CC-5013, IMiD3) augments anti-CD40 SGN-40-induced cytotoxicity in human multiple myeloma: clinical implications. Cancer Res. (2005) 65:11712-20. doi: 10.1158/0008-5472.CAN-05-1657

45. Chan AC, Neeson P, Leeansyah E, Tainton K, Quach H, Prince HM, et al. Natural killer $\mathrm{T}$ cell defects in multiple myeloma and the impact of lenalidomide therapy. Clin Exp Immunol. (2014) 175:4958. doi: 10.1111/cei.12196

46. Attal M, Richardson PG, Rajkumar SV, San-Miguel J, Beksac M, Spicka I, et al. Isatuximab plus pomalidomide and low-dose dexamethasone versus pomalidomide and low-dose dexamethasone in patients with relapsed and refractory multiple myeloma (ICARIA-MM): a randomised, multicentre, open-label, phase 3 study. Lancet. (2019) 394:2096-107. doi: 10.1016/S0140-6736(19)32556-5

47. Chari A, Suvannasankha A, Fay JW, Arnulf B, Kaufman JL, Ifthikharuddin $\mathrm{JJ}$, et al. Daratumumab plus pomalidomide and dexamethasone in relapsed and/or refractory multiple myeloma. Blood. (2017) 130:97481. doi: 10.1182/blood-2017-05-785246

48. Dimopoulos MA, Dytfeld D, Grosicki S, Moreau P, Takezako N, Hori M, et al. Elotuzumab plus pomalidomide and dexamethasone for multiple myeloma. $N$ Engl J Med. (2018) 379:1811-22. doi: 10.1056/NEJMoa1805762

49. Dimopoulos MA, Oriol A, Nahi H, San-Miguel J, Bahlis NJ, Usmani SZ, et al. Daratumumab, lenalidomide, and dexamethasone for multiple myeloma. $N$ Engl J Med. (2016) 375:1319-31. doi: 10.1056/NEJMoa1607751

50. Nijhof IS, Lammerts van Bueren JJ, van Kessel B, Andre P, Morel Y, Lokhorst HM, et al. Daratumumab-mediated lysis of primary multiple myeloma cells is enhanced in combination with the human anti-KIR antibody IPH2102 and lenalidomide. Haematologica. (2015) 100:2638. doi: 10.3324/haematol.2014.117531

51. Plesner T, Arkenau HT, Gimsing P, Krejcik J, Lemech C, Minnema $\mathrm{MC}$, et al. Phase $1 / 2$ study of daratumumab, lenalidomide, and dexamethasone for relapsed multiple myeloma. Blood. (2016) 128:1821-8. doi: 10.1182/blood-2016-07-726729

52. Lonial S, Vij R, Harousseau JL, Facon T, Moreau P, Mazumder A, et al. Elotuzumab in combination with lenalidomide and low-dose dexamethasone in relapsed or refractory multiple myeloma. J Clin Oncol. (2012) 30:19539. doi: 10.1200/JCO.2011.37.2649
53. Richardson PG, Jagannath S, Moreau P, Jakubowiak AJ, Raab MS, Facon $\mathrm{T}$, et al. Elotuzumab in combination with lenalidomide and dexamethasone in patients with relapsed multiple myeloma: final phase 2 results from the randomised, open-label, phase 1b-2 dose-escalation study. Lancet Haematol. (2015) 2:e516-27. doi: 10.1016/S2352-3026(15)00197-0

54. Song W, van der Vliet HJ, Tai YT, Prabhala R, Wang R, Podar $\mathrm{K}$, et al. Generation of antitumor invariant natural killer $\mathrm{T}$ cell lines in multiple myeloma and promotion of their functions via lenalidomide: a strategy for immunotherapy. Clin Cancer Res. (2008) 14:6955-62. doi: 10.1158/1078-0432.CCR-07-5290

55. Gorgun G, Samur MK, Cowens KB, Paula S, Bianchi G, Anderson JE, et al. Lenalidomide enhances immune checkpoint blockade-induced immune response in multiple myeloma. Clin Cancer Res. (2015) 21:460718. doi: 10.1158/1078-0432.CCR-15-0200

56. Ray A, Das DS, Song Y, Richardson P, Munshi NC, Chauhan D, et al. Targeting PD1-PDL1 immune checkpoint in plasmacytoid dendritic cell interactions with T cells, natural killer cells and multiple myeloma cells. Leukemia. (2015) 29:1441-4. doi: 10.1038/leu.2015.11

57. Liu J, Hamrouni A, Wolowiec D, Coiteux V, Kuliczkowski K, Hetuin D, et al. Plasma cells from multiple myeloma patients express B7-H1 (PDL1) and increase expression after stimulation with IFN-\{gamma\} and TLR ligands via a MyD88-, TRAF6-, and MEK-dependent pathway. Blood. (2007) 110:296-304. doi: 10.1182/blood-2006-10-051482

58. Tamura H, Ishibashi M, Yamashita T, Tanosaki S, Okuyama N, Kondo A, et al. Marrow stromal cells induce B7-H1 expression on myeloma cells, generating aggressive characteristics in multiple myeloma. Leukemia. (2013) 27:464-72. doi: 10.1038/leu.2012.213

59. Mateos M-V, Orlowski RZ, Siegel DSD, Reece DE, Moreau P, Ocio EM, et al. Pembrolizumab in combination with lenalidomide and low-dose dexamethasone for relapsed/refractory multiple myeloma (RRMM): final efficacy and safety analysis. J Clin Oncol. (2016) 34 (15_suppl):8010. doi: 10.1200/JCO.2016.34.15_suppl.8010

60. Badros AZ, Kocoglu MH, Ma N, Rapoport AP, Lederer E, Philip S, et al. A phase II study of anti PD-1 antibody pembrolizumab, pomalidomide and dexamethasone in patients with relapsed/refractory multiple myeloma (RRMM). Blood. (2015) 126:506. doi: 10.1182/blood.V126.23.506.506

61. Gormley NJ, Pazdur R. Immunotherapy combinations in multiple myeloma - known unknowns. N Engl J Med. (2018) 379:17915. doi: 10.1056/NEJMp1803602

62. Oriol A. A critical evaluation of pembrolizumab in addition to lenalidomide and dexamethasone for the treatment of multiple myeloma. Expert Rev Hematol. (2020) 13:435-45. doi: 10.1080/17474086.2020.1744432

63. Rosenblatt J, Avivi I, Vasir B, Uhl L, Munshi NC, Katz T, et al. Vaccination with dendritic cell/tumor fusions following autologous stem cell transplant induces immunologic and clinical responses in multiple myeloma patients. Clin Cancer Res. (2013) 19:3640-8. doi: 10.1158/1078-0432.CCR-13-0282

64. Xie X, Chen Y, Hu Y, He Y, Zhang H, Li Y. Lenalidomide augments the antitumor activities of Eps8 peptide-specific cytotoxic T lymphocytes against multiple myeloma. Mol Cancer Ther. (2019) 18:2258-69. doi: 10.1158/1535-7163.MCT-19-0424

65. Martiniani R, Di Loreto V, Di Sano C, Lombardo A, Liberati AM. Biological activity of lenalidomide and its underlying therapeutic effects in multiple myeloma. Adv Hematol. (2012) 2012:842945. doi: 10.1155/2012/842945

66. Gupta D, Treon SP, Shima Y, Hideshima T, Podar K, Tai YT, et al. Adherence of multiple myeloma cells to bone marrow stromal cells upregulates vascular endothelial growth factor secretion: therapeutic applications. Leukemia. (2001) 15:1950-61. doi: 10.1038/sj.leu.2402295

67. Hideshima T, Bergsagel PL, Kuehl WM, Anderson KC. Advances in biology of multiple myeloma: clinical applications. Blood. (2004) 104:60718. doi: 10.1182/blood-2004-01-0037

68. Nijhof IS, van de Donk N, Zweegman S, Lokhorst HM. Current and new therapeutic strategies for relapsed and refractory multiple myeloma: an update. Drugs. (2018) 78:19-37. doi: 10.1007/s40265-017-0841-y

69. Kumar SK, Dimopoulos MA, Kastritis E, Terpos E, Nahi H, Goldschmidt H, et al. Natural history of relapsed myeloma, refractory to immunomodulatory drugs and proteasome inhibitors: a multicenter IMWG study. Leukemia. (2017) 31:2443-8. doi: 10.1038/leu.2017.138 
70. Zhu YX, Braggio E, Shi CX, Bruins LA, Schmidt JE, Van Wier $\mathrm{S}$, et al. Cereblon expression is required for the antimyeloma activity of lenalidomide and pomalidomide. Blood. (2011) 118:4771-9. doi: 10.1182/blood-2011-05-356063

71. Heintel D, Rocci A, Ludwig H, Bolomsky A, Caltagirone S, Schreder M, et al. High expression of cereblon (CRBN) is associated with improved clinical response in patients with multiple myeloma treated with lenalidomide and dexamethasone. Br J Haematol. (2013) 161:695-700. doi: 10.1111/bjh.12338

72. Zhou N, Gutierrez-Uzquiza A, Zheng XY, Chang R, Vogl DT, Garfall AL, et al. RUNX proteins desensitize multiple myeloma to lenalidomide via protecting IKZFs from degradation. Leukemia. (2019) 33:2006-21. doi: 10.1038/s41375-019-0403-2

73. Bjorklund CC, Ma W, Wang ZQ, Davis RE, Kuhn DJ, Kornblau SM, et al. Evidence of a role for activation of Wnt/beta-catenin signaling in the resistance of plasma cells to lenalidomide. J Biol Chem. (2011) 286:1100920. doi: 10.1074/jbc.M110.180208

74. Ocio EM, Fernandez-Lazaro D, San-Segundo L, Lopez-Corral L, Corchete LA, Gutierrez NC, et al. In vivo murine model of acquired resistance in myeloma reveals differential mechanisms for lenalidomide and pomalidomide in combination with dexamethasone. Leukemia. (2015) 29:705-14. doi: 10.1038/leu.2014.238

75. Zhu YX, Shi CX, Bruins LA, Wang X, Riggs DL, Porter B, et al. Identification of lenalidomide resistance pathways in myeloma and targeted resensitization using cereblon replacement, inhibition of STAT3 or targeting of IRF4. Blood Cancer J. (2019) 9:19. doi: 10.1038/s41408-019-0173-0

76. Hansen JD, Correa M, Nagy MA, Alexander M, Plantevin V, Grant V, et al. Discovery of CRBN E3 ligase modulator CC-92480 for the treatment of relapsed and refractory multiple myeloma. J Med Chem. (2020) 63:664876. doi: 10.1021/acs.jmedchem.9b01928

77. Lonial S, Donk NWCJvd, Popat R, Zonder JA, Minnema MC, Larsen J, et al. First clinical (phase 1b/2a) study of iberdomide (CC-220; IBER), a CELMoD, in combination with dexamethasone (DEX) in patients (pts) with relapsed/refractory multiple myeloma (RRMM). J Clin Oncol. (2019) 37 (15_suppl):8006. doi: 10.1200/JCO.2019.37.15_suppl. 8006

78. Rasco DW, Papadopoulos KP, Pourdehnad M, Gandhi AK, Hagner PR, Li Y, et al. A first-in-human study of novel cereblon modulator avadomide
(CC-122) in advanced malignancies. Clin Cancer Res. (2019) 25:908. doi: 10.1158/1078-0432.CCR-18-1203

79. Bjorklund CC, Kang J, Amatangelo M, Polonskaia A, Katz M, Chiu H, et al. Iberdomide (CC-220) is a potent cereblon E3 ligase modulator with antitumor and immunostimulatory activities in lenalidomide- and pomalidomideresistant multiple myeloma cells with dysregulated CRBN. Leukemia. (2020) 34:1197-201. doi: 10.1038/s41375-019-0620-8

80. Van De Donk N, Popat R, Larsen J, Minnema MC, Jagannath S, Oriol A, et al. First results of iberdomide (IBER; CC-220) in combination with dexamethasone (DEX) and daratumumab (DARA) or bortezomib (BORT) in patients with relapsed/refractory multiple myeloma (RRMM). Blood. (2020) 136 (Suppl. 1):16-17. doi: 10.1182/blood-2020-137743

81. Dimopoulos K, Sogaard Helbo A, Fibiger Munch-Petersen H, Sjo L, Christensen J, Sommer Kristensen L, et al. Dual inhibition of DNMTs and $\mathrm{EZH} 2$ can overcome both intrinsic and acquired resistance of myeloma cells to IMiDs in a cereblon-independent manner. Mol Oncol. (2018) 12:18095. doi: 10.1002/1878-0261.12157

82. Caraccio C, Krishna S, Phillips DJ, Schurch CM. Bispecific antibodies for multiple myeloma: a review of targets, drugs, clinical trials, and future directions. Front Immunol. (2020) 11:501. doi: 10.3389/fimmu.2020.00501

83. Gagelmann N, Riecken K, Wolschke C, Berger C, Ayuk FA, Fehse B, et al Development of CAR-T cell therapies for multiple myeloma. Leukemia. (2020) 34:2317-32. doi: 10.1038/s41375-020-0930-x

Conflict of Interest: PN received research funding from Bristol Myers Squibb.

The remaining authors declare that the research was conducted in the absence of any commercial or financial relationships that could be construed as a potential conflict of interest.

Copyright (C) 2021 D'Souza, Prince and Neeson. This is an open-access article distributed under the terms of the Creative Commons Attribution License (CC BY). The use, distribution or reproduction in other forums is permitted, provided the original author(s) and the copyright owner(s) are credited and that the original publication in this journal is cited, in accordance with accepted academic practice. No use, distribution or reproduction is permitted which does not comply with these terms. 